\title{
DISPONIBILIDADE DE POTÁSSIO EM SOLOS PARA CAPIM-BRAQUIÁRIA CULTIVADO EMI VASOS ${ }^{(1)}$
}

BERNARDO VAN RAIJ (2) e JOSÉ ANTônio QUAGGIO (2), Seção de Fertilidade do Solo, Instituto Agronômico.

\section{RESUMO}

Procurou-se testar a hipótese de que o potássio trocável seria a única forma do nutriente disponivel para o capim-braquiária (Brachiaria decumbens Stapf.) nos solos estudados. Foram utilizadas amostras superficiais de seis solos com horizonte B latossólico, nove com horizonte B textural e um orgânico, bem como amostras do horizonte $B$ de sete solos com $B$ textural e de um Latossolo. O ensaio foi feito com vasos de 2 litros de terra, obtendo-se três cortes do capim. Analisou-se o potássio trocável no solo no início e no final do ensaio e determinou-se o potássio absorvido pela parte aérea do capim. A absorção de potássio em geral superoil a diminuição da quantidade de potássio trocável, entre o início e c. fim do experimento, em cerca de $50 \%$ para as amostras superficiais e em mais de duas vezes para as amostras do horizonte $B$, chegando a dez vezes mais em um caso. Não obstante isso, excluindo-se uma amostra de solo que teve comportamento excepcional, o potássio absorvido apresentou alta correlação com a quantidade trocável, tanto para o primeiro corte $(\mathrm{r}=0,911)$ como para a soma dos três cortes $(r=0,913)$. Concluiu-se que a planta aproveitou quantidades de potássio que superaram os teores trocáveis dos solos, principalmente de amostras do horizonte $\mathrm{B}$ de podzólicos.

(1) Trabalho apresentado no XIX Congresso Brasileiro de Ciência do Solo, realizado em Curitiba (PR), de 17 a 24 de julho de 1983. Recebido para publicacão a 6 de julho de 1983.

(2) Com bolsa de suplementação do CNPq. 


\section{INTRODUÇĀO}

A avaliação da disponibilidade de potássio em solos é comumente feita analisando o teor trocável do elemento em amostras coletadas na camada arável. Tal procedimento é conveniente e tem-se revelado satisfatório para muitas situaçōes, conforme mostra o trabalho de rev!são de RAIJ (13).

Existe, contudo, o conhecimento de que formas não trocáveis de potássio podem-se tornar disponíveis, existindo no solo um equilíbrio do tipo:

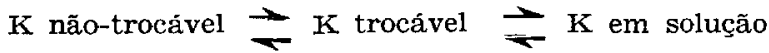

A participação do potássio não-trocável na reposição do trocável depende dos minerais contendo potássio existentes no solo (8). Em solos de clima temperado, a participação pode ser muito importante, havendo a manutenção de um nível mínimo de potássio trocável às custas do não-trocável (4). Mesmo em solos do Brasil, tem sido constatada a absorção de potássio por plantas em quantidades excedendo ao teor trocável, como verificado por CRISÓSTOMO \& CASTRO (3) para solos do Ceará e OLIVETRA et alii (12) para o Rio Grande do Sul.

Para os solos do Estado de São Paulo, CATANI (1) constatou que os teores trocáveis de 25 amostras superficiais de solos variaram de 27 a $223 \mathrm{mg} / \mathrm{kg}$ de terra, enquanto os teores totais eram muito mais elevados, entre 281 e $14.076 \mathrm{mg} / \mathrm{kg}$ de terra, sugerindo a existência de minerais contendo potássio nesses solos. LEPSCH et alii (5) verificaram, para solos com horizonte B textural da Estação Experimental de Pindorama, que os teores de potássio solúvel em ácido nítrico a quente, freqüentemente tomados como estimativa do potássio ilão-trocável de reserva, superavam muito os teores trocáveis. Os autores atribuíram o fato à presença de mica nas frações argila e limo e de feldspato potássico nas frações areia e limo.

Neste trabalho fez-se um estudo em vasos, para testar a hipótese de que apenas o teor trocável seria a fonte de potássio disponivel do solo, para amostras superficiais e do horizonte B de scios do Estado de São Paulo.

\section{MATERIAL E MẼTODOS}

Para este estudo foram utilizadas amostras superficiais, retiradas de 0 a $20 \mathrm{~cm}$ de seis solos com horizonte B latossólico, rove solos com horizonte $B$ textural e de um solo orgânico, bem como amostras do horizonte B de solos com B textural e de um latossolo. Detalhes sobre estas amostras estão no quadro 1. 
QUADRO 1. Informações sobre os solos utilizados no estudo de disponibilidade de potássio

\begin{tabular}{|c|c|c|}
\hline $\mathrm{N}^{\circ}$ & Legenda & Especificação \\
\hline 1 & LEa & $\begin{array}{l}\text { Latossolo Vermelho-Escuro textura média, amostra superficial, } \\
\text { vegetação de campo, municipio de Orlândia. }\end{array}$ \\
\hline 11 & LE & $\begin{array}{l}\text { Latossolo Vermelho-Escuro - orto, unidade Limeira, amostra su- } \\
\text { perficial, mata original da Estação Experimental de Cordeirópolis. }\end{array}$ \\
\hline 12 & LRe & $\begin{array}{l}\text { Latossolo Roxo eutrófico, amostra superficial do perfil } 1245 \text { da } \\
\text { folha de Leme do Levantamento do Estado. Mata latifoliada. }\end{array}$ \\
\hline 35 & LRe & Idem, horizonte $\mathrm{B}$. \\
\hline 13 & LRd & $\begin{array}{l}\text { Latossolo Roxo distrófico, amostra superficial da unidade Ingazei- } \\
\text { ro, Estação Experimental de Ribeirão Preto. Clilturas anuais. }\end{array}$ \\
\hline 22 & LV & $\begin{array}{l}\text { Latossolo Vermelho-Amarelo, amostra superficial de cerrado. Cen- } \\
\text { tro Experimental de Campinas. }\end{array}$ \\
\hline 25 & LH & $\begin{array}{l}\text { Latossolo Vermelho-Amarelo húmico, unidade Ouro Preto, amostra } \\
\text { superficial da Estação Experimental de Monte Alegre do Sul. } \\
\text { Plantação de nectarina. }\end{array}$ \\
\hline
\end{tabular}

$6 \quad \mathrm{H}$

Solo hidromórfico de Registro, amostra superficial. Culturas anuais.

$9 \quad$ TE

Terra Roxa Estruturada, amostra superficial do perfil 1197 da folha de Campinas do Levantamento de Solos do Estado. Vegetação de gramineas, municipio de Paulínia.

10 TE Idem, horizonte $B, 70-80 \mathrm{~cm}$.

7 PmI Podzolizado de Lins e Marilia - variação Marilia, unidade Serrinha, amostra superficial do perfil 1083 do Levantamento da Estação Experimental de Pindorama. Solo coberto por gramíneas.

$8 \quad$ Pml Idem, horizonte $\mathrm{B}_{22}, 75-100 \mathrm{~cm}$.

14 Pml Podzolizađo de Lins e Marilia - variação Marilia, unidade Pindorama, amostra superficial do perfil 902 do Levantamento de Solos da Estação Experimental de Pindorama. Cafezal.

15 Pml Idem, horizonte $B_{22,2}, 75-100 \mathrm{~cm}$.

16 PV Podzólico Vermelho-Amarelo - orto, unidade Videira, amostra superficial do perfil 985 do Levantamento Pedológico da Estação Experimental de Jundiaí. Culturas anuais.

17 PV Idem, horizonte $B_{22}, 70 \mathrm{~cm}$.

$20 \quad P \ln$

Podzolizado de Lins e Marília - variação Lins, unidade Jacaima, amostra superficial do perfil 1081 do Levantamento de Solos da Estação Experimental de Pindorama. Grama-batatais.

26 Pe Podzolizado com cascalhos, amostra superficial, municipio de Campinas. Bosque secundário.

$27 \quad \mathrm{Pc} \quad$ Idem, horizonte $\mathrm{B}, 30-50 \mathrm{~cm}$.

continua 
QUADRO 1. Conclusão

\begin{tabular}{|c|c|c|}
\hline $\mathrm{N}^{\circ}$ & Legenda & Especificaçāo \\
\hline 29 & PVls & $\begin{array}{l}\text { Podzólico Vermelho-Amarelo - variação Laras, amostra super- } \\
\text { ficial próxima do perfil } n^{\circ} 7 \text { do Levantamento de Reconhecimento } \\
\text { de Solos do Estado de São Paulo. }\end{array}$ \\
\hline 30 & PVp & $\begin{array}{l}\text { Podzólico Vermelho-Amarelo - variação Piracicaba, amostra su- } \\
\text { perficial do perfil } \mathrm{n}^{\circ} 5 \text { do Levantamento de Iíeconhecimento de } \\
\text { Solos do Estado de São Paulo. Mato. }\end{array}$ \\
\hline 36 & PVp & $\begin{array}{l}\text { Podzólico Vermelho-Amarelo - variação Piracicaba, unidade ola- } \\
\text { ria, amostra superficial, quadrícula de Araras, município de Cor- } \\
\text { deirópolis. Cana-de-açúcar. }\end{array}$ \\
\hline 33 & $\mathrm{PV}$ & $\begin{array}{l}\text { Podzólico Vermelho-Amarelo _ orto, município de Jaguariúna, } \\
\text { horizonte } \mathrm{B}, 50-100 \mathrm{~cm} \text {. Eucalipto. }\end{array}$ \\
\hline 24 & $\mathrm{PV}$ & $\begin{array}{l}\text { Podzólico Vermelho-Amarelo - orto, unidade Monte Alegre do } \\
\text { Levantamento da Estação Experimental de Monte Alegre do Sul, } \\
\text { horizonte B, 16-29cm. Mato. }\end{array}$ \\
\hline
\end{tabular}

Diversas delas se referem a levantamentos de solo do Estado de São Paulo, já efetuados ou em andamento. Os publicados são o Levantamento de Reconhecimento de Solos do Estado de Sãi) Paulo (2), os das Estações Experimentais de Limeira (11), Ribeirão Prcto (10), Monte Alegre do Sul (15), Pindorama (6), Jundiaí (16), e o da Quadrícula de Campinas (9).

As amostras de solo foram peneiradas e colocadas em vasos de alumínio, acondicionando-se 2 litros de terra por vaso e colocando-se em $4 \mathrm{~g}$ de superfosfato triplo e solução fornecendo $100 \mathrm{mg}$ de $\mathrm{N}$-nítrico e $20 \mathrm{mg}$ de S. As amostras 22, 24,27, 30 e 33 receberam aplicaçāo de calcário. Para cada solo foram feitas três repetiçōes. Plantaram-se por vaso três mudas de capim-braquiária (Brachiaria decumbens Stapf.) oriundas da germinação de sementes em vermiculita. As aplicações de $\mathrm{N}$ e $\mathrm{S}$ foram repetidas mais cinco vezes durante o desenvolvimento do experimento.

Amostrou-se o solo antes e no final do ensaio e efetuaram-se análises pelos métodos descritos por RAIJ \& ZULLO (14). Foram determinadas as densidades globais dos solos do vaso e da medida de volume usada no laboratório, para poder calcular as quantidades de potássio trocável existentes nos vasos. O capim foi seco, pesado e moído, determinando-se o potássio total absorvido pela parte aérea.

\section{RESULTADOS E DISCUSSÃO}

No quadro 2 são indicados os resultados de análise de solo, especificamente os teores de argila, matéria orgânica, cálcio e magnésio, bem como os teores de potássio no início e no final do ensaio. São também indicadas as quantidades de potássio absorvido pelo capim, nos três cortes. 


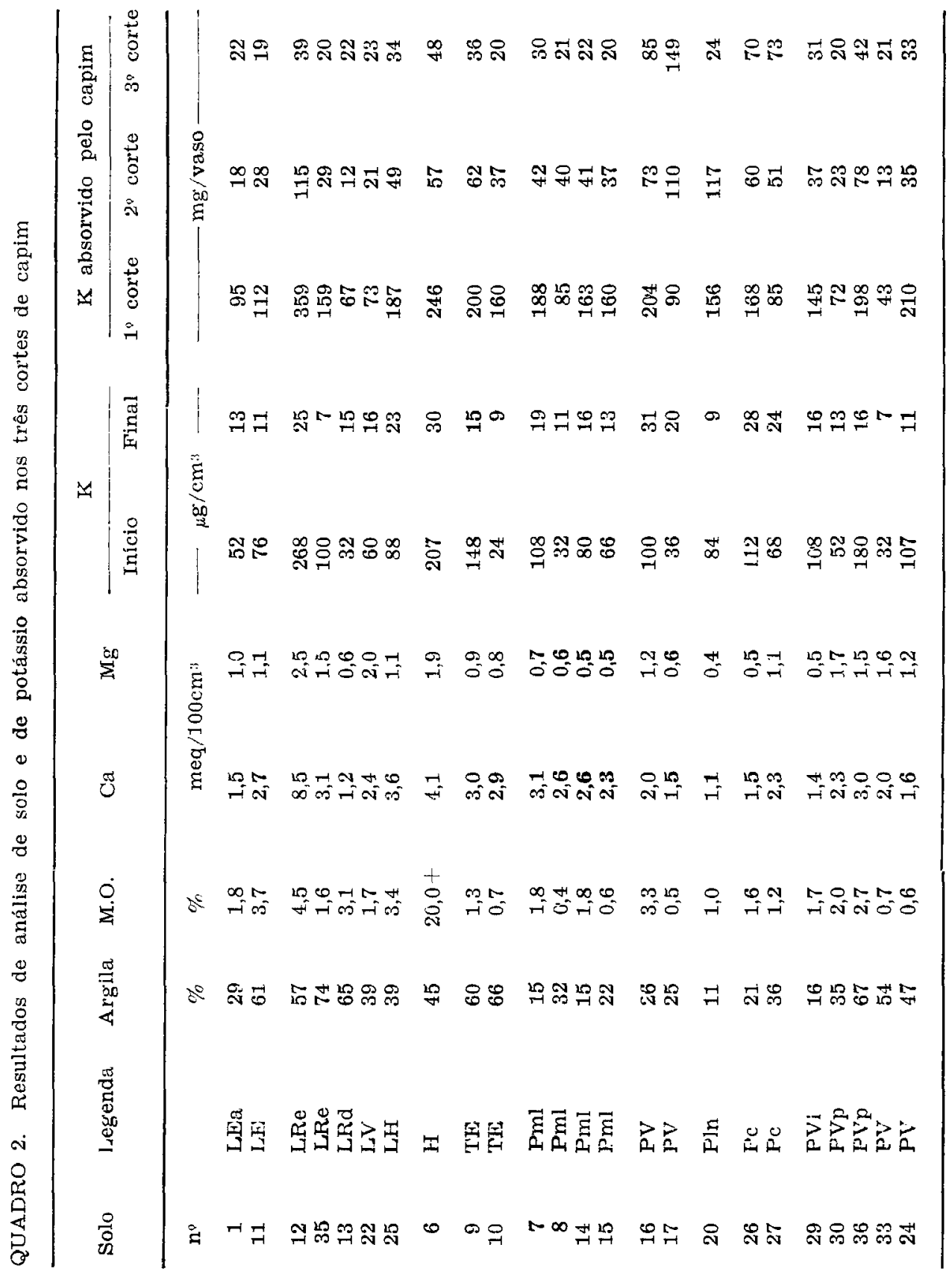


De forma geral, na maioria dos solos, houve uma absorção bem maior de potássio no primeiro corte, como, aliás, era de esperar. Contudo, nota-se alguma variação desse comportamento, no caso do Podzolizado com cascalhos e, principalmente, no Podzólico Vermelho-Amarelo de Jundiaí (amostras 16 e 17). No último caso, no horizonte $B$, houve elevada liberação de potássio, com aumento de absorção. Nos demais solos, seus teores, após o ensaio, atingiram valores muito baixos, e isso está coerente com a menor absorção no terceiro corte. Em alguns casois, o teor trocável no solo pode não ser um parâmetro suficiente para se avaliar a disponibilidade de potássio, como bem mostran! os casos das amostras $16,17,26$ e 27.

Excluindo-se apenas a amostra 17, houve correlacōes altamente significativas entre o potássio absorvido pela planta e $c$ teor trocável inicial no solo, com valores do coeficiente de correlação de 0,911 para o primeiro corte e de 0,913 para os três cortes. Nesse particular, os solos diferem dos de clima temperado, nos quais as reservas de potássio não-trocável que se podem tornar disponiveis sāo importantes, de tal forma que o teor trocável pode não apresentar alta correlação com o potássio absorvido pela planta (4). Neste caso, pode, também, ter influído o fato de gramíneas em geral apresentarem-se: como pouco eficientes na absorção de potássio de formas não-trocáveis ( $\boldsymbol{y}$ ).

No quadro 3 é mostrado um balanço do potássio, comparando-se as quantidades trocáveis existentes no inicio e no final do ensaio nos solos, com as quantidades absorvidas pelo capim. Com algumas exceçoes, nota-se que a diminuição do teor trocável no solo é inferior ao potássio absorvido, o que mostra que há alguma contribuição de formas não-trocáveis. Este fato é indicado pela relação entre o potássio absorvido e a diminuição do teor trocável, que foi em geral maior do que um. A absorção de formas não-trocáveis foi maior nos solos com horizonte $B$ textural e, nestes, maior no horizonte $B$.

No caso dos podzolizados de Lins e Marilia, LEPSCH et alii (5) realizaram estudos mineralógicos e de formas de potássio em três dos perfis utilizados neste trabalho, determinando a constituição mineralógica, o potássio trocável e o potássio solúvel em ácido nítrico a quente, considerado como potássio de reserva. Os solos apresentaram mica na fração argila e feldspato potássico na fração areia, que são minerais contendo potássio. No caso do perfil 902, os teores trocáveis e de reserva foram 52 e $28 \mathrm{meq} / 100 \mathrm{~g}$ para o horizonte A e 28 e 256 para o horizonte $B_{\%_{1}}$. Note-se que as amostras deste trabalho não são exatamente as mesmas, embora coletadas no mesmo local. Niesmo assim, a comparação com os resultados obtidos, para as amostras 14 e 15 do

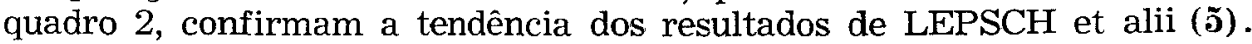
Já nos casos dos perfis 1081 e 1083, correspondentes às cimostras 20 e 7 neste trabalho, o teste biológico acusou valores insignificantes de reservas de potássio no solo, enquanto, no trabalho citado, elas são duas a três vezes maiores que o teor trocável. 


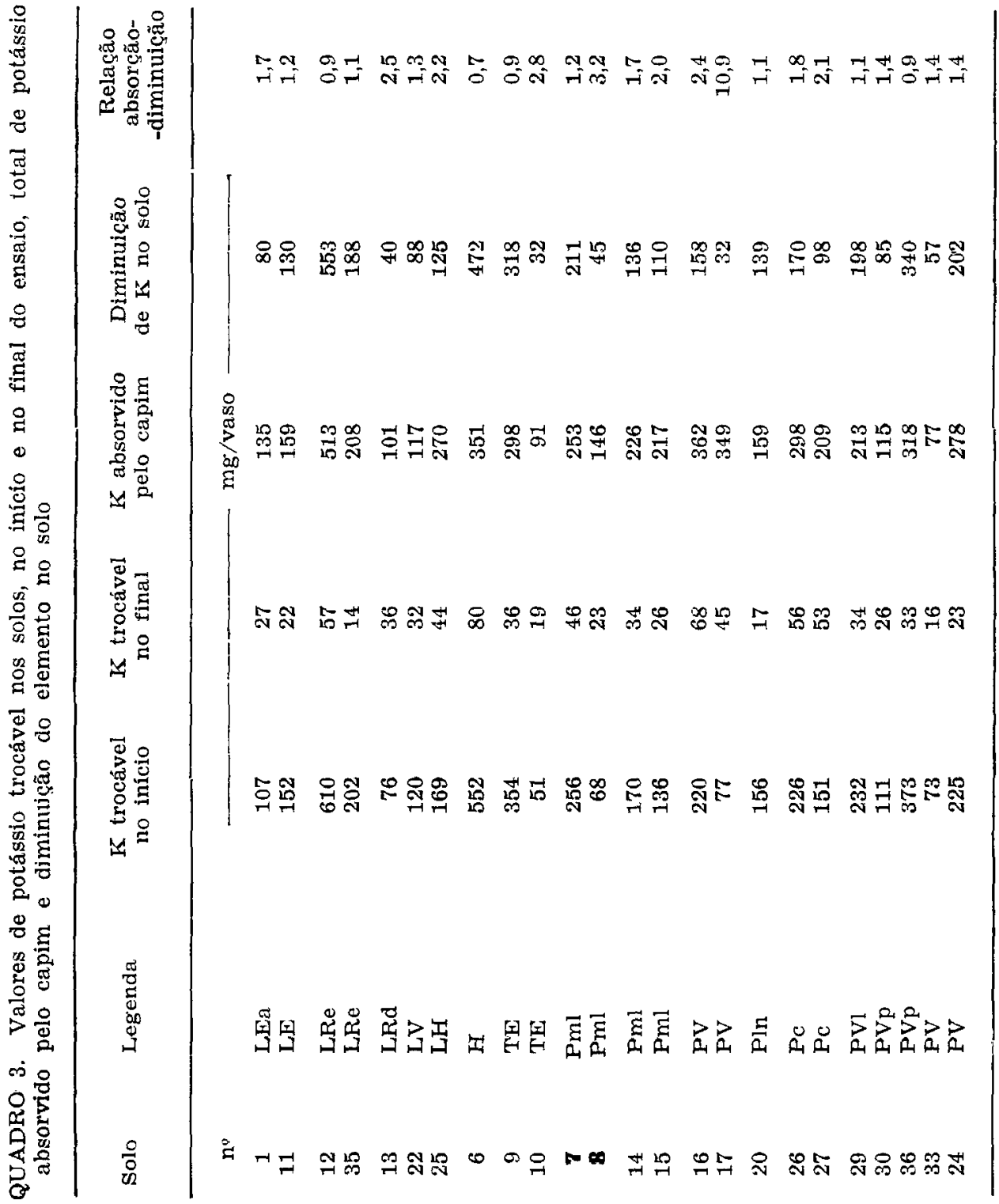


De qualquer maneira, os resultados deste trabalho indicam que existem consideráveis quantidades de potássio disponível $€ m$ certos solos, em formas não-trocáveis na camada arável e em formas trocáveis e não-trocáveis nas camadas mais profundas. Tal fato aponta a necessidade de essa situação ser levada em conta em trabalhos de pesquisa, a fim de que possam ser estabelecidos critérios mais abrangentes de diagnose do potássio no solo. E possível que mapas de solos suficientemente detalhados possam ter grande utilidade na generalização dessas informações.

\section{SUMMARY}

\section{AVAILABILITY OF POTASSIUM IN SOILS FOR SIGNAL GRASS GROWN IN POTS}

The hypothesis that exchangeable potassium is the cnly available source of this element for Brachiaria decumbens Stapf. was tested in a pot experiment. Surface and B horizon samples of Latosols and Podzolic soils were used. Soil exchangeable potassium in the beginning and at the end of the experiment was measured and the amount of potassium taken up by the above-ground parts of the plants was calculated. Potassium uptake by the plants was generally higher than the change in the amount of soil exchangeable potassium by about $50 \%$ for the surface soil samples and more than twice for samples of the $E$ horizon of the Podzolic soils. Nevertheless, a high correlation was observed ketween uptake of potassium and exchangeable potassium for 23 out of the 24 soil samples, with a correlation coefficient of 0.91 . It was concluded that part of the non-exchangeable potassium is available for plants in the soils studied.

\section{REFERENCIAS BIBLIOGRAFICAS}

1. CATANI, R.A. Estudos de potássio nos solos do Estado de São Paulo; extrato de tese do concurso para cadeira de química analitica. Piracicaba, Escola Superior de Agricultura «Luiz de Queiroz», 1955. 39p.

2. CENTRO NACIONAL DE ENSINO E PESQUISAS AGRONOMMICAS. Comissão de Solos. Levantamento de reconhecimento dos so'os do Estado de São Paulo. Rio de Janeiro, Serviço Nacional de Pesquisas Agronômicas, 1960. 634p. (SNPA, Boletim, 12)

3. CRISóstomo, L.A. \& CASTRO, A.F. Poder de suprimeñto de potássio de solos da zona fisiográfica de Baturité, CE, Brasil. Turrialba, Costa Rica, $20: 425-433,1970$.

4. GRTMME, H. \& NEMETH, $K$. The evaluation of soil $K$ status by means of soil testing. In: CONGRESS OF THE INTERNATIONAL POTASH INSTITUTE, 11., Bern, 1978. Proceedings. p.99-108.

5. LEPSCH, I.F.; ROTTA, C.L.; VALADARES, J.M.A.S. Mineralogia e formas de potássio em solos da Estação Experimental de Pindorama, SP. Revista Brasileira de Ciência do Solo, Campinas, z:63-68, 1978.

6. — \& VALAdARES, J.M.A.S. Levantamento pedológico da Estação Experimental de Pindorama. Bragantia, Campinas, 35:13-40, 1976. 
7. MENGEL, K. Fatores e processos que afetam as necessidades do potássio das plantas. In: YAMADA, $\mathbf{T}$. et alii, ed. Potåssio na Agricultura Brasileira. Piracicaba, Instituto da Potassa \& Fosfato; Instituto Internacional da Potassa, 1982. p.195-212.

8. MIELNICZUK, J. O potássio no solo. Piracicaba, Institut. da Potassa \& Fosfato (EUA); Instituto Internacional da Potassa (Suiça), 1978. 80p. (Boletim Técnico, 2)

9. OLIVEIRA, J.B. de; MENK, J.R.F.; ROTTA, C.L. Levantamento pedológico semidetalhado dos solos do Estado de São Paulo - Quadricula de Campinas. Rio de Janeiro, IBGE-SUPREN, 1976. 156p. (Série Recursos Naturais $\epsilon$ Meio Ambiente, 5)

10. __ \& MONIZ, A.C. Levantamento pedológico detalhado da Estaçāo Experimental de Ribeirão Preto, SP. Bragantia, Campinas, 34:59-114, 1975.

11. —— ROTTA, C.L. Levantamento peđológico detalhado da Estação Experimental de Limeira, São Paulo. Bragantia, Campinas, 32:1-60, 1973.

12. OLIVEIRA, V.; LUDWICK, A.E.; BEATTY, M.T. Potassium removed from Southern Brazilian soils by exaustive cropping and chemical extraction methods. Soil Science Society of America Proceedings, 35:763-767, 1971.

13. RAIJ, B. van. Disponibilidade de potássio em solos do Brasil. In: SIMPósIo SOBRE POTÁSSIO NA AGRICULTURA BRASILEIRA, 1. Londrina, 1982. Anais. Piracicaba, Instituto da Potassa \& Fosfato; Instituto Internacional da Potassa, 1982. p.67-76.

14. \& ZULLO, M.A.T. Métodos de análise de solo para fins de fertilidade. Campinas, Instituto Agronômico, 1977. 16p. (Circular, 63)

15. ROTTA, C.L.; JORGE, J.A.; OLIVEIRA, J.B. de; KüPPER, A. Levantamento pedológico detalhado da Estação Experimental de Monte Alegre do Sul, Săo Paulo. Bragantia, Campinas, 30:215-276, 1971.

16. VALADARES, J.M.A.S.; LEPSCH, I.F.; KÜPPER, A. Levantamento pedológico detalhado da Estação Experimental de Jundiai, São Paulo. Bragantia, Campinas, 30:337-387, 1971. 